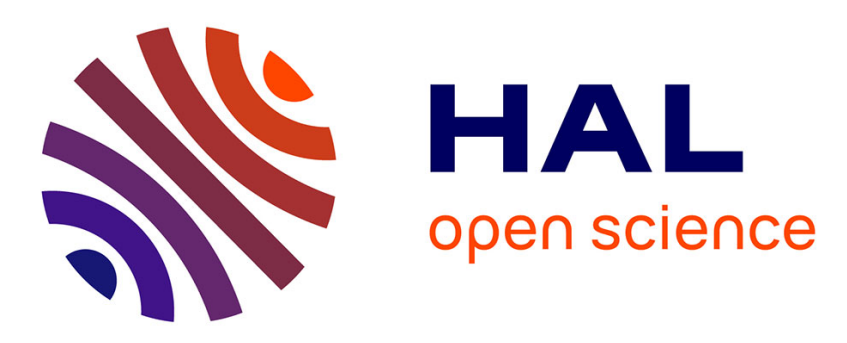

\title{
Miscibility study in stable and metastable orientational disordered phases in a two-component system (CH3) $\mathrm{CCl} 3+\mathrm{CCl} 4$
}

\author{
Luis C. Pardo, M. Barrio, Josep Lluis Tamarit, D. O. Lopez, J. Salud, \\ Philippe Négrier, Denise Mondieig
}

\section{To cite this version:}

Luis C. Pardo, M. Barrio, Josep Lluis Tamarit, D. O. Lopez, J. Salud, et al.. Miscibility study in stable and metastable orientational disordered phases in a two-component system $(\mathrm{CH} 3) \mathrm{CCl} 3+\mathrm{CCl} 4$. Chemical Physics Letters, 1999, 308 (3-4), pp.204-210. 10.1016/S0009-2614(99)00627-2 . hal-01550398

\section{HAL Id: hal-01550398 \\ https://hal.science/hal-01550398}

Submitted on 3 Jan 2018

HAL is a multi-disciplinary open access archive for the deposit and dissemination of scientific research documents, whether they are published or not. The documents may come from teaching and research institutions in France or abroad, or from public or private research centers.
L'archive ouverte pluridisciplinaire HAL, est destinée au dépôt et à la diffusion de documents scientifiques de niveau recherche, publiés ou non, émanant des établissements d'enseignement et de recherche français ou étrangers, des laboratoires publics ou privés.

\section{다(1)(2)}

Distributed under a Creative Commons Attribution - ShareAlikel 4.0 International 


\title{
Miscibility study in stable and metastable orientational disordered phases in a two-component system $\left(\mathrm{CH}_{3}\right) \mathrm{CCl}_{3}+\mathrm{CCl}_{4}$
}

\author{
L.C. Pardo a, M. Barrio a, J.Ll. Tamarit ${ }^{\text {a, }}{ }^{\text {, }}$, D.O. López ${ }^{\text {a }}$, J. Salud ${ }^{\text {a }}$, P. Negrier ${ }^{\text {b }}$, \\ D. Mondieig ${ }^{\mathrm{b}}$ \\ a Departament de Física i Enginyeria Nuclear, E.T.S.E.I.B., Universitat Politècnica de Catalunya, Diagonal, 647, E-08028 Barcelona, \\ Catalonia, Spain \\ ${ }^{\mathrm{b}}$ Centre de Physique Moléculaire, Optique et Hertzienne, UMR 5798 au CNRS-Université Bordeaux I, 351, cours de la Libération, \\ F-33405 Talence Cedex, France
}

\begin{abstract}
The orientationally disordered stable and metastable mixed crystals of the two-component system methylchloroform $\left(\left(\mathrm{CH}_{3}\right) \mathrm{CCl}_{3}\right)+$ carbon tetrachloride $\left(\mathrm{CCl}_{4}\right)$ have been characterised from a crystallographic and thermodynamic point of view. The monotropic behaviour of the metastable phase in the pure components is maintained for the whole range of composition. The lattice symmetry of the stable orientationally disordered phase of methylchloroform has been found to be isostructural with that of the carbon tetrachloride compound. Continuous series of both stable and metastable mixed crystals give rise to a double isomorphism relationship, one for the stable state and another for the metastable stable of the pure components.
\end{abstract}

\section{Introduction}

Orientational disorder in crystals is usually found when molecules of nearly spherical symmetry are arranged in a high-symmetry lattice [1]. The methylchloromethane compounds, $\left(\mathrm{CH}_{3}\right)_{4-n} \mathrm{CCl}_{n}$, where $n$ varies from 0 to 4 , as such, belong to this class of material and are known to exhibit a number of solid-solid phase transitions [2-4]. Compounds with $n=2,3,4$ are particularly fascinating substances which display two orientationally disordered (OD) phases with two (close) melting points $\sim 5 \mathrm{~K}$ apart. On cooling, methylchloromethanes crystallise to an

\footnotetext{
* Corresponding author. Fax: +34-93-401-66-00; e-mail: tamarit@fen.upc.es
}

OD phase (Ia) and upon further cooling to another OD phase (Ib). When cooling is limited such that phase Ia is formed, this phase Ia melts on heating without passing back through phase Ib. In the same way, when heated from phase Ib a new melting point several degrees higher than that of phase Ia is obtained. Consequently phase Ia is a monotropic phase. This monotropic behaviour was found earlier by Rudman and Post [3,4] from X-ray diffraction and differential scanning calorimetry measurements. The former showed high-symmetry lattices (rhombohedral and cubic) for both OD Ib stable phases as well as for both OD Ia phases (face-centered cubic, FCC). The latter indicated low values of entropy of fusion, a typical feature of OD phases. The differences between the metastable (Ia) and stable (Ib) 
phases were unambiguously demonstrated by optical birefringence measurements [5], where $\Delta n$ for phase $\mathrm{Ib}$ was found two orders of magnitude larger than for phase Ia. Additional Raman [6] and Brillouin scattering $[7,8]$ experiments have shown both the differences and similarities between stable and metastable OD phases.

An analysis of the birefringence on the mixed non-cubic OD crystals (Ib) has been performed in the $\left(\mathrm{CH}_{3}\right) \mathrm{CCl}_{3}+\mathrm{CCl}_{4}[9,10]$ and $\left(\mathrm{CH}_{3}\right)_{2} \mathrm{CCl}_{2}+$ $\mathrm{CCl}_{4}$ [11] two-component systems in spite of the lack of binary phase diagrams. The authors of these works have demonstrated that in Ib mixed crystals weak preferred orientations of molecules are present, the concentration range, of the orientational order parameter. The calculation of this order parameter was based on the assumption of the existence of continuous solid solutions in the non-cubic Ib phase as well as in the linear dependence of the density of the continuous mixed crystals. In the particular case of the $\left(\mathrm{CH}_{3}\right) \mathrm{CCl}_{3}+\mathrm{CCl}_{4}$ two-component system, the first assumption was clearly unjustified due to the symmetry differences between the Ib phases of $\left(\mathrm{CH}_{3}\right) \mathrm{CCl}_{3}$ (simple cubic) and $\mathrm{CCl}_{4}$ (rhombohedral) according to the work of Rudman and co-workers [2-4]. Moreover, their work established that for the mixed crystal $\left[\left(\mathrm{CH}_{3}\right) \mathrm{CCl}_{3}\right]_{0}{ }_{9}\left[\mathrm{CCl}_{4}\right]_{01}$, the $\mathrm{OD} \mathrm{Ib}$ phase becomes cubic because both the orientational order parameter as well as the birefringence are equal to zero.

In the present Letter, we will demonstrate that phase $\mathrm{Ib}$ of $\left(\mathrm{CH}_{3}\right) \mathrm{CCl}_{3}$ is isostructural with phase $\mathrm{Ib}$ of $\mathrm{CCl}_{4}$ and, moreover, that both phases are isomorphous. The same isomorphism relationship will be established for the OD FCC phases Ia.

\section{Experimental}

Special grade $\left(\mathrm{CH}_{3}\right) \mathrm{CCl}_{3}$ and $\mathrm{CCl}_{4}$ were supplied by the Aldrich Chemical and were always treated under an Ar atmosphere without additional purification.

A Perkin-Elmer DSC-7 differential scanning calorimeter equipped with a home-made low-temperature adapter was used. In order to prevent sample reaction with the container, as well as to avoid undesirable effects on the thermograms due to the high vapour pressure of the compounds, high-pressure stainless-steel pans (also from Perkin-Elmer) were used. The measurements were performed with heating and cooling rates of $2 \mathrm{~K} \mathrm{~min}^{-1}$ and with sample masses around $25 \mathrm{mg}$.

$\mathrm{X}$-ray powder diffraction data were obtained from a horizontally mounted INEL cylindrical positionsensitive detector (CPS-120) [12] equipped with a liquid-nitrogen INEL CRY950 crysostat. The 4096 channels of the detector, used in Debye-Scherrer geometry gives an angular step of $\sim 0.03(2 \theta)$. As recommended [13] external calibration using cubic phase $\mathrm{Na}_{2} \mathrm{Ca}_{3} \mathrm{Al}_{2} \mathrm{~F}_{4}$ was performed by means of cubic spline fittings. The peak positions were determined by pseudo-Voight fittings. Acquisition times were 120 min for standard measurements. Additional patterns with acquisition times of $1320 \mathrm{~min}$ were performed to account for the lattice symmetry of the stable OD phase Ib of $\left(\mathrm{CH}_{3}\right) \mathrm{CCl}_{3}$. The liquid samples were introduced into $0.3 \mathrm{~mm}$ diameter Lindemann capillaries which were rotated perpendicularly to the X-ray beam during the experiments in order to improve the averaging of crystallites. Helium gas was used as heat exchanger in the sample chamber.

\section{Polymorphism of the pure components}

\section{1. $\mathrm{CCl}_{4}$}

The lattice symmetry of the stable OD Ib phase was early determined by Rudman as rhombohedral with $Z=21$ and lattice parameters $a=14.4 \AA$ and $\alpha \approx 90^{\circ}$ [2]. The results of the present work agree quite well with the previous published, with $a=$ $14.431 \AA$ and $\alpha=89.41^{\circ}$ at $232.2 \mathrm{~K}$. For the metastable OD FCC phase Ia, a lattice parameter of $8.333 \AA$ at $230.2 \mathrm{~K}$ was found, which is close to the value of $8.34 \AA$ at $238 \mathrm{~K}$ of Ref. [14].

Concerning the transformation temperatures, the values obtained were $225.7 \pm 0.4,250.1 \pm 0.4$ and $245.5 \pm 0.5 \mathrm{~K}$ for $\mathrm{II}-\mathrm{Ib}, \mathrm{Ib}-\mathrm{L}$ and $\mathrm{Ia}-\mathrm{L}$, respectively. The corresponding enthalpy changes were determined to be $4.68 \pm 0.10,2.53 \pm 0.05$ and 1.82 $\pm 0.04 \mathrm{~kJ} \mathrm{~mol}^{-1}$, respectively. Temperatures as well as enthalpy changes agree with data published elsewhere $[4,15,16]$. 


\section{2. $\left(\mathrm{CH}_{3}\right) \mathrm{CCl}_{3}$}

According to Rudman and Post [2] the crystal system of the OD stable phase, solely from X-ray diffraction evidence of $\left(\mathrm{CH}_{3}\right)_{4-n} \mathrm{CCl}_{n}$ for $n=2,3,4$, could be indexed as cubic. However, an optical examination of the crystals indicated to Rudman and Post that "only $\left(\mathrm{CH}_{3}\right) \mathrm{CCl}_{3}$ was optically isotropic". Recent measurements $[9,10]$ have shown that birefringence is not zero for this phase. Nevertheless it must be pointed out that such a parameter also has a contribution due to the anisotropy of the polarizability of the molecules (called molecular birefringence). Accurate measurements (with acquisition times of $1320 \mathrm{~min})$ show that the OD phase Ib of $\left(\mathrm{CH}_{3}\right) \mathrm{CCl}_{3}$ is isostructural with phase $\mathrm{Ib}$ of $\mathrm{CCl}_{4}$. According to the unambiguous similarity of the patterns, the phase $\mathrm{Ib}$ of methylchloroform was indexed and lattice parameters corresponding to a rhombohedral structure [R] were determined to be $a=14.584 \AA$ and $\alpha=$ $89.49^{\circ}$ at $232.2 \mathrm{~K}$. Table 1 gathers the observed and calculated spacings for this phase $\mathrm{Ib}$. With regard to the metastable phase Ia, the face-centered cubic lattice parameter was close $(8.418 \AA$ at $230.2 \mathrm{~K})$ to that previously published (8.39 $\AA$ at $224.2 \mathrm{~K})$ [3].

The characteristic temperatures and enthalpy changes associated with the $\mathrm{II}-\mathrm{Ib}, \mathrm{Ib}-\mathrm{L}$ and $\mathrm{Ia}-\mathrm{L}$ transitions were found to be in accord with the published data [4,17]. The transition temperatures are

Table 1

Experimental $\left(d_{\text {exp }}\right)$ and calculated $\left(d_{\text {cal }}\right)$ lattice spacings (in ångström) for the reflections ( $h k l)$ of the OD rhombohedral stable phase of $\left(\mathrm{CH}_{3}\right) \mathrm{CCl}_{3}$ compound at $232.2 \mathrm{~K}$

\begin{tabular}{rrlllr}
\hline \multicolumn{1}{r}{$h k l$} & & & $d_{\text {obs }}$ & $d_{\text {cal }}$ & \multicolumn{1}{c}{$d_{\text {obs }}-d_{\text {cal }}$} \\
\hline-2 & 2 & 0 & 5.13322 & 5.13277 & 0.00045 \\
2 & 2 & 1 & 4.90465 & 4.89936 & 0.00529 \\
3 & 0 & 0 & 4.86382 & 4.86062 & 0.00320 \\
2 & -2 & 1 & 4.84091 & 4.84158 & -0.00068 \\
3 & 1 & 0 & 4.62470 & 4.62346 & 0.00120 \\
3 & -1 & 0 & 4.59833 & 4.59898 & -0.00064 \\
3 & 1 & 1 & 4.41740 & 4.42160 & -0.00420 \\
3 & -1 & 1 & 4.39165 & 4.39305 & -0.00141 \\
3 & 2 & 1 & 3.92587 & 3.92458 & 0.00128 \\
-3 & -2 & 1 & 3.90306 & 3.89963 & 0.00343 \\
3 & -2 & 1 & 3.88605 & 3.88489 & 0.00116 \\
4 & 1 & 0 & 3.54154 & 3.54401 & -0.00248 \\
3 & 1 & 4 & 2.87765 & 2.87844 & -0.00079 \\
-3 & 1 & 4 & 2.84867 & 2.84907 & -0.00041
\end{tabular}

$224.0 \pm 0.2,241.9 \pm 0.2$ and $235.8 \pm 0.3 \mathrm{~K}$, respectively. The associated enthalpy changes are $7.38 \pm$ $0.12,2.31 \pm 0.03$ and $1.55 \pm 0.03 \mathrm{~kJ} \mathrm{~mol}^{-1}$, respectively.

Although no effort has been made to characterise the possible low-temperature mixed crystals, several patterns of pure components in phase II were collected in order to verify the known lattice symmetries as well as to check the influence of the sample preparation. The results obtained were $a=20.190$ $\AA, b=11.380 \AA, c=19.800 \AA$ and $\beta=111.45^{\circ}$ for the monoclinic $\mathrm{C} 2 / \mathrm{c}$ lattice of $\mathrm{CCl}_{4}$, and $a=11.555$ $\AA, b=7.996 \AA$ and $c=5.856 \AA$ for the orthorhombic Pnma lattice of $\left(\mathrm{CH}_{3}\right) \mathrm{CCl}_{3}$. Both results agree with published data $[18,19]$.

\section{Stable and metastable mixed crystals}

\subsection{Crystallographic study}

In order to demonstrate the isomorphism between the isostructural OD rhombohedral stable phases of $\left(\mathrm{CH}_{3}\right) \mathrm{CCl}_{3}$ and $\mathrm{CCl}_{4}$, lattice parameters were measured as a function of composition at $232.2 \mathrm{~K}$. Results for the $\boldsymbol{a}$ and $\alpha$ parameters are shown in Fig. 1a.

In the same way, the isomorphism between the isostructural OD FCC metastable phases was proved, as can be inferred from the continuity of the lattice parameter against concentration (see Fig. 1b).

Two facts must be emphasized from this study. On the one hand, the monotropic behaviour of the Ia phase is maintained for the whole concentration range. On the other hand, the packing relation between the stable and metastable phases found in pure components is also unchanged, i.e. metastable FCC mixed crystals have a lower packing coefficient than the stable rhombohedral mixed crystals.

The established isomorphism between the stable OD phases validates the continuity of the order parameter determined by Struts [9,10]. Moreover, the additional assumption in that work on the linear dependence of the density for the stable mixed crystals is fully verified. Nevertheless, there is no mole fraction for which the stable mixed crystals become cubic as was inferred from the evolution of the order parameter against mole fraction and from the optical 
birefringence for the molecular alloy $\left[\left(\mathrm{CH}_{3}\right) \mathrm{CCl}_{3}\right]_{0} 9^{-}$ $\left[\mathrm{CCl}_{4}\right]_{01}$. As indicated by the author, the case when optical birefringence is zero can be explained assuming compensation between the contribution of the different molecular species of the molecular alloy. No explanation can be found for the zero value of the order parameter $S$ at $X=0.1$ mole fraction of $\mathrm{CCl}_{4}\left(X_{0}=0.9\right.$ mole fraction of $\left(\mathrm{CH}_{3}\right) \mathrm{CCl}_{3}$ in the original work). The errors for the order parameter variations against concentration were probably underestimated.

\subsection{Thermodynamic analysis}

From differential scanning calorimetric measurements, the temperatures of the OD stable rhombohedral plus liquid $[\mathrm{R}+\mathrm{L}]$ and OD metastable FCC plus liquid $[\mathrm{FCC}+\mathrm{L}]$ equilibria have been built up (see Fig. 2).

As far as we know, this is the first time two continuous solid solutions corresponding to stable and metastable mixed crystals have been obtained. Such a fascinating behaviour enabled us to achieve coherent thermodynamic information on two different structurally ordered mixed crystals formed by the
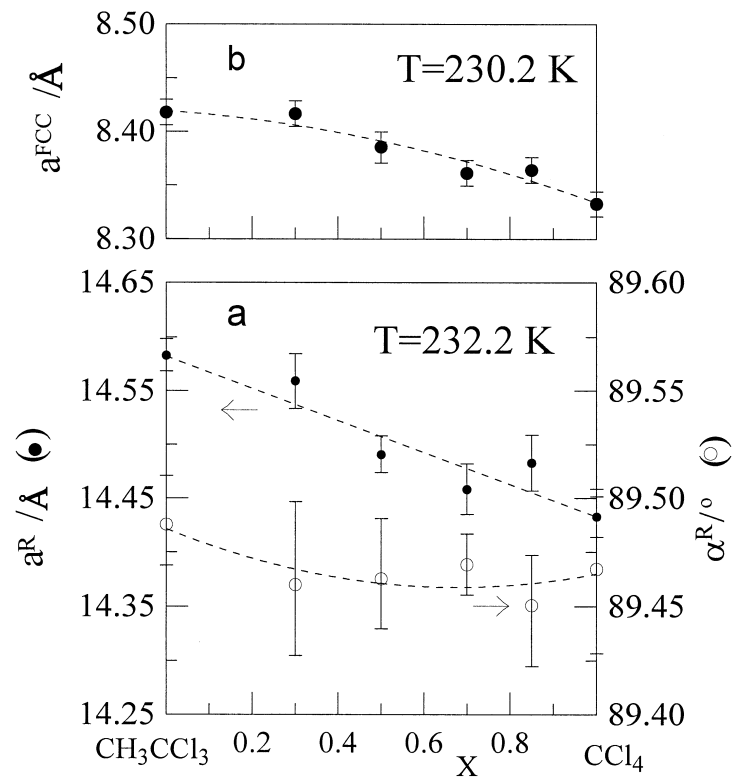

Fig. 1. Lattice parameters $\boldsymbol{a}$ and $\alpha$ for the rhombohedral at 232.2 $\mathrm{K}$ (a) and for the FCC (b) mixed crystals at $230.2 \mathrm{~K}$ as a function of the mole fraction.

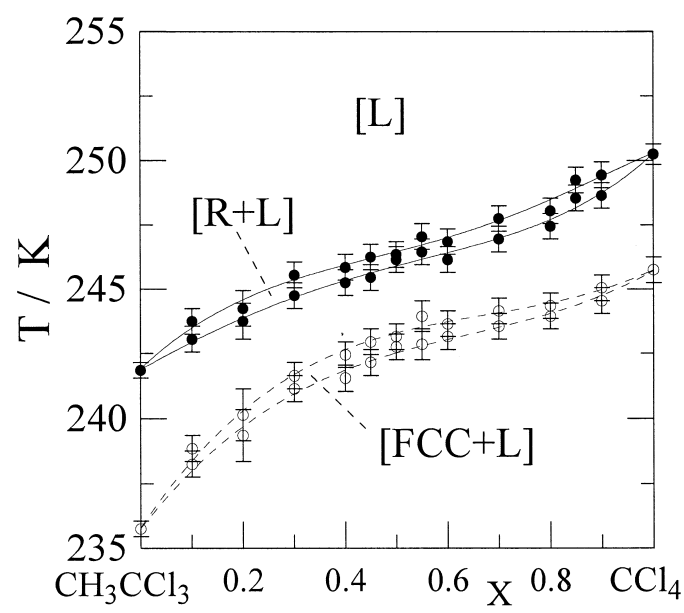

Fig. 2. Stable $[\mathrm{R}+\mathrm{L}](\mathbf{O})$ and metastable $[\mathrm{FCC}+\mathrm{L}](\mathrm{O})$ equilibria for the two-component system $\left(\mathrm{CH}_{3}\right) \mathrm{CCl}_{3}+\mathrm{CCl}_{4}$.

same molecules. Under isobaric conditions, the thermodynamic properties of the mixed states are known if the Gibbs energy of each mixture is known. Let us consider the continuous series (isomorphism is stated) of the OD mixed crystals $\alpha$ ( $\mathrm{R}$ or FCC in our case) between the pure components A and B. The Gibbs energy relationship for a mixture of $(1-X)$ moles of $\mathrm{A}$ and $X$ moles of $\mathrm{B}$, is given by

$$
\begin{aligned}
G^{\alpha} & (T, X) \\
= & (1-X) \mu_{\mathrm{A}}^{*, \alpha}+X \mu_{\mathrm{B}}^{*, \alpha}+R T[(1-X) \\
& \times \ln (1-X)+X \ln X]+G^{\mathrm{E}, \alpha}(T, X),
\end{aligned}
$$

where $\mu_{\mathrm{A}}^{*, \alpha}$ and $\mu_{\mathrm{B}}^{*, \alpha}$ represent the molar Gibbs energies of the pure components $\mathrm{A}$ and $\mathrm{B}$, respectively, $R$ is the gas constant and $G^{\mathrm{E}, \alpha}(T, X)$ is the excess Gibbs energy.

To determine the two-phase equilibrium region between two phases $\alpha$ and $\mathrm{L}$, the rule corresponding to the minimum Gibbs energy of the mixture $\mathrm{A}_{1-X} \mathrm{~B}_{X}$ at each $T$ must be applied. To analyse the two-phase equilibrium, the equal Gibbs curve method (EGC) was used [20]. The difference between the Gibbs energies (Eq. (1)) of the $\alpha$ and L phases can be written as

$$
\begin{aligned}
\Delta G^{\alpha \rightarrow \mathrm{L}}(T, X)= & G^{\mathrm{L}}(T, X)-G^{\alpha}(T, X) \\
= & (1-X) \Delta \mu_{\mathrm{A}}^{*}(T)+X \Delta \mu_{\mathrm{B}}^{*}(T) \\
& +\Delta G^{\mathrm{E}}(T, X),
\end{aligned}
$$


where $\Delta \mu_{i}^{*}$ is $\mu_{i}^{*, \mathrm{~L}}-\mu_{i}^{*, \alpha} \quad(i=\mathrm{A}, \mathrm{B})$ and $\Delta G^{\mathrm{E}}(T, X)$ is the excess Gibbs energy difference between $\mathrm{L}$ and $\alpha$ phases, i.e., $G^{\mathrm{E}, \mathrm{L}}(T, X)-$ $\mathrm{G}^{\mathrm{E}, \alpha}(T, X)$.

Eq. (2) equals zero when both $G^{\mathrm{L}}(T, X)$ and $G^{\alpha}(T, X)$ are equal, which at each $X$ mole fraction takes place at a defined temperature, named the EGC-temperature $\left(T_{\mathrm{EGC}}(X)\right)$. By assuming that $\Delta \mu_{i}^{*}(T)$ can be approximately written as $\Delta S_{i}^{*}\left(T_{i}^{\alpha \rightarrow \mathrm{L}}-T\right)$, where $T_{i}^{\alpha \rightarrow \mathrm{L}}$ is the melting temperature of the $\alpha$ phase for the component $i$ and $\Delta S_{i}^{*}$ is the melting entropy, the equation $\Delta G\left(T_{\mathrm{EGC}}, X\right)=0$ provides the EGC temperature as:

$$
\begin{aligned}
T_{\mathrm{EGC}}(X)= & \frac{(1-X) \Delta H_{\mathrm{A}}^{*}-X \Delta H_{\mathrm{B}}^{*}}{(1-X) \Delta S_{\mathrm{A}}^{*}+X \Delta S_{\mathrm{B}}^{*}} \\
& +\frac{\Delta G_{\mathrm{EGC}}^{\mathrm{E}}(X)}{(1-X) \Delta S_{\mathrm{A}}^{*}+X \Delta S_{\mathrm{B}}^{*}},
\end{aligned}
$$

where $\Delta H_{i}{ }^{*}$ is the enthalpy change of fusion for the $i$ component.

A first estimation of the EGC curve can be done from the experimental data of the $[\alpha+\mathrm{L}]$ equilibrium. An iterative procedure (performed by means of the WINIFIT program [21] based on Oonk's method [20]) enables one to obtain reasonable $\Delta G_{\mathrm{EGC}}^{\mathrm{E}}(X)$ values. This procedure was applied to the $[\mathrm{R}+\mathrm{L}]$ and $[\mathrm{FCC}+\mathrm{L}]$ equilibria.

In this framework, the description of the excess Gibbs energy for the R and FCC phases was given by a two-parameter function in the form of a Redlich-Kister polynomial

$G^{E, \alpha}(X)=X(1-X)\left[G_{1}+G_{2}(1-2 X)\right]$,

which in the lack of strong local anomalies is fairly adequate and physically understandable. As far as thermodynamic excess properties of the liquid phase are concerned, both excess enthalpy and excess Gibbs energy were previously determined $[22,23]$. The experimental values have been fitted by means of a second-order Redlich-kister polynomial (see Table 2).

From the excess Gibbs energy differences obtained from the thermodynamic analysis of the $[\mathrm{R}+$ $\mathrm{L}]$ and $[\mathrm{FCC}+\mathrm{L}]$ equilibria and the excess Gibbs
Table 2

$G_{1}$ and $G_{2}$ parameters of the Redlich-Kister polynomial for the excess Gibbs energy of the liquid [L] state and rhombohedral [R] and face-centered cubic [FCC] OD mixed crystals

\begin{tabular}{lll}
\hline Phase & $\begin{array}{l}G_{1} \\
\left(\mathrm{~J} \mathrm{~mol}^{-1}\right)\end{array}$ & $\begin{array}{l}G_{2} \\
\left(\mathrm{~J} \mathrm{~mol}^{-1}\right)\end{array}$ \\
\hline$[\mathrm{L}]$ & 330 & -143 \\
{$[\mathrm{R}]$} & 340 & -187 \\
{$[\mathrm{FCC}]$} & 290 & -202 \\
\hline
\end{tabular}

energy of the liquid state, the excess Gibbs energy for the R and FCC mixed crystals were obtained (see Table 2).

The calculated Gibbs energies are strictly valid at $T_{\mathrm{EGC}}(X=0.5)$ of the respective equilibria. A temperature dependence of such functions can be obtained by the definition of the $G^{\mathrm{E}}(T, X)$ function: $G^{\mathrm{E}}(T, X)=H^{\mathrm{E}}(X)-T \cdot S^{\mathrm{E}}(X)$, where excess enthalpy, $H^{\mathrm{E}}(X)$ and excess entropy $S^{\mathrm{E}}(X)$ are considered temperature-independent magnitudes. The former can be roughly obtained for $\mathrm{R}$ and FCC mixed crystals from their melting enthalpy changes and the available data of the excess enthalpy of the liquid state [22]. A similar procedure enables us to obtain the same functional temperature dependence for the excess Gibbs energy of the liquid mixture. In order to establish unambiguously the hierarchy of the phase stability at a given temperature, the Gibbs energies must be compared taking into account the temperature dependence. Nevertheless, in the present case, both $[\mathrm{R}+\mathrm{L}]$ and $[\mathrm{FCC}+\mathrm{L}]$ equilibria are close to one another. It is then quite obvious that such a temperature dependence can be avoided if an intermediate temperature is taken for the analysis. In our case $T=244.75 \mathrm{~K}$, which corresponds to the mean value between the two equimolar EGC temperatures of the $[\mathrm{R}+\mathrm{L}], T_{\mathrm{EGC}}(X=0.5)=246.35 \mathrm{~K}$, and $[\mathrm{FCC}+\mathrm{L}], T_{\mathrm{EGC}}(X=0.5)=243.15 \mathrm{~K}$, has been chosen.

The Gibbs energies of the stable [R] and metastable $[\mathrm{FCC}]$ mixed crystals plus a linear contribution $-\left[(1-X) \mu_{\mathrm{A}}^{*, \mathrm{~L}}+X \mu_{\mathrm{B}}^{*}, \mathrm{~L}\right]$ [20], which only shift both Gibbs energy values identically, are depicted in Fig. 3a. As can be inferred from this figure, the $\mathrm{R}$ mixed crystals are more stable than the FCC mixed crystals, which demonstrates again that the monotropy of FCC mixed crystals is concentration- 
independent. In Fig. 3b, the difference at $244.75 \mathrm{~K}$ between both shifted Gibbs energies is shown. It is essential to realise that the lowest difference is given around 0.3 mole fraction of $\mathrm{CCl}_{4}$. Such a region corresponds to the concentration domain where the $\mathrm{R}$ mixed crystals are closer, from a thermodynamic point of view, to the FCC mixed crystals. It must be emphasised that according to the optical birefringence $(\Delta n)$ measurements the order parameter was found to be zero at about $X=0.1$ mole fraction of $\mathrm{CCl}_{4}\left(X_{0}=0.9\right.$ mole fraction of $\left(\mathrm{CH}_{3}\right) \mathrm{CCl}_{3}$ in the original work). Actually, the optical birefringence contains the molecular (anisotropy of the molecular polarizability) and the structural (anisotropy of the crystalline field) birefringence. If an excess optical birefringence is defined as $\Delta n^{\mathrm{E}}(X)=$ $\Delta n(X)-\left[(1-X) \Delta n_{\mathrm{A}}+X \Delta n_{\mathrm{B}}\right]$, where $\Delta n_{\mathrm{A}}$ and $\Delta n_{\mathrm{B}}$ are the optical birefringence of the components $\mathrm{A}$ and $\mathrm{B}$, respectively, the changes on the crystalline field due to the mixed crystal formation can be accounted for, assuming that the anisotropy of the molecular polarizability will be roughly the same.
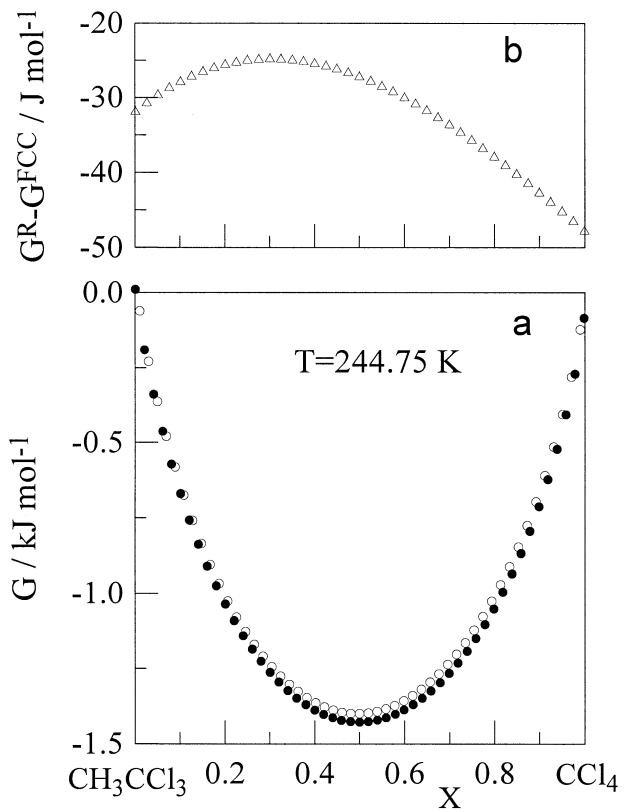

Fig. 3. The Gibbs energy plus the linear contribution (see text) for the R ( ) and FCC (O) mixed crystals (a) and Gibbs energy difference between R and FCC $(\Delta)$ mixed crystals (b) at 244.75 K.

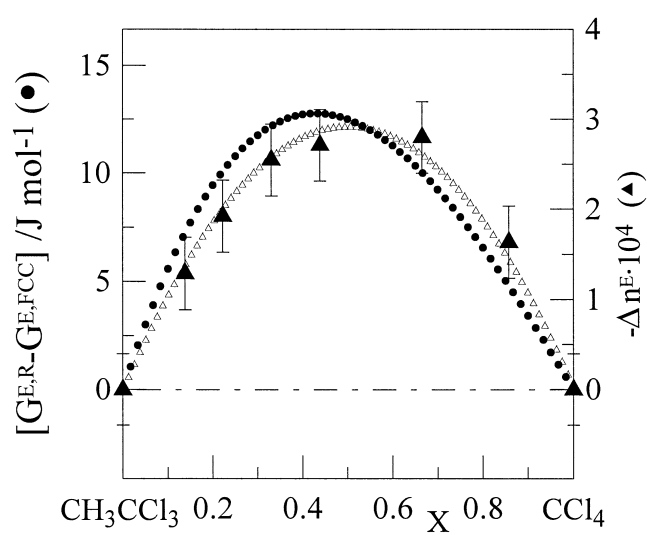

Fig. 4. Excess Gibbs energy of the R mixed crystals referred to the excess Gibbs energy of the cubic (FCC) mixed crystals (O) and 'excess' optical birefringence ( $\boldsymbol{\Delta}$ ) (see the text for definition) calculated from Ref. [10].

From a thermodynamic point of view, the excess Gibbs energy of $\mathrm{R}$ mixed crystals minus the excess Gibbs energy of the FCC mixed crystals, must account for the anisotropy of the intermolecular interactions, assuming that the steric contribution is quite similar in R and FCC mixed crystals. In Fig. 4, we plot the excess Gibbs energy difference between $\mathrm{R}$ and FCC mixed crystals together with the $\Delta n^{\mathrm{E}}(X)$ values obtained from Ref. [10]. From an inspection of Fig. 4, it clearly follows that the excess optical birefringence is well correlated to the excess Gibbs energy of the R mixed crystals referred to the FCC mixed crystals.

\section{Conclusions}

The lattice of the stable OD phase of $\left(\mathrm{CH}_{3}\right) \mathrm{CCl}_{3}$ has been found to be isostructural with the stable OD phase of $\mathrm{CCl}_{4}$, i.e., rhombohedral symmetry. In addition, continuous OD stable rhombohedral mixed crystals have been obtained.

Concerning the OD metastable phases of $\left(\mathrm{CH}_{3}\right) \mathrm{CCl}_{3}$ and $\mathrm{CCl}_{4}$, both $\mathrm{FCC}$, form also continuous series of mixed crystals which, moreover, are found to be monotropic in the whole concentration range. Such a conclusion has been reinforced by the thermodynamic analysis which shows that the Gibbs energy of the $\mathrm{R}$ phase is lower than the corresponding Gibbs energy of the FCC phase, whatever the 
composition is. This conclusion is against the previous result of Struts $[9,10]$, that a cubic lattice was inferred around the 0.1 mole fraction of $\mathrm{CCl}_{4}$. In spite of this clear discrepancy, the thermodynamic analysis has revealed that in the low range of $\mathrm{CCl}_{4}$ content, the $\mathrm{R}$ and FCC mixed crystals are more similar from a thermodynamic point of view.

\section{References}

[1] N.G. Parsonage, L.A.K. Stavely, Disorder in Crystals, Clarendon, Oxford, 1978.

[2] R. Rudman, B. Post, Mol. Cryst. 5 (1968) 95.

[3] R. Rudman, Mol. Cryst. Liq. Cryst. 6 (1970) 427.

[4] L. Silver, R. Rudman, J. Chem. Phys. 74 (1970) 3134.

[5] Y. Koga, J.A. Morrison, J. Chem. Phys 62 (1975) 3359.

[6] A. Anderson, B.H. Torrie, W.S. Tse, Chem. Phys. Lett. 61 (1979) 119.

[7] M. Djabourov, C. Levy-Manneheim, J. LeBlond, P. Papon, J. Chem. Phys. 66 (1977) 5748.

[8] J. Zuk, H. Kiefte, M.J. Clouler, J. Chem. Phys. 95 (1991) 1950.
[9] A.V. Struts, O.F. Bezrukov, Chem. Phys. Lett. 232 (1995) 181.

[10] A.V. Struts, Phys. Rev. B 51 (1995) 5673.

[11] M.N. Akimov, O.F. Bezrukov, O.V. Chikunov, A.V. Struts, J. Chem. Phys. 95 (1991) 22.

[12] J. Ballon, V. Comparat, J. Pouxe, Nucl. Instrum. Methods 217 (1983) 213.

[13] M. Evain, P. Deniard, A. Jouanneaux, R. Brec, J. Appl. Crystallogr. 26 (1993) 563.

[14] B. Post, Acta Crystallogr. 12 (1959) 349.

[15] J.A. Morrison, E.L. Richards, J. Chem. Thermodyn. 8 (1976) 1033.

[16] J.B. Ott, D.L.J. Cardon, J. Chem. Thermodyn. 8 (1976) 505.

[17] R.J.L. Andon, J.F. Counsell, D.A. Lee, J.F. Martin, J. Chem. Soc., Faraday Trans. I 69 (1973) 1721.

[18] L. Silver, R. Rudman, J. Chem. Phys. 57 (1972) 210.

[19] S. Cohen, R. Powers, R. Rudman, Acta Crystallogr. B 35 (1978) 1670.

[20] H.A.J. Oonk, Phase Theory, Elsevier, Amsterdam, 1981.

[21] R. López, D.O. López, wINIFIT Computer Program, Polytechnical University of Catalonia, Barcelona, 1998.

[22] J.C. van Miltenburg, J.H. Obbink, E.L. Meijer, J. Chem. Thermodyn. 11 (1979) 37.

[23] E.L. Meijer, N. Brouwer, J.C. van Miltenburg, J. Chem. Thermodyn. 8 (1976) 703. 